\title{
Apparent Diffusion Coefficient Levels and Neurodevelopmental Outcome in Fetuses with Brain MR Imaging White Matter Hyperintense Signal
}

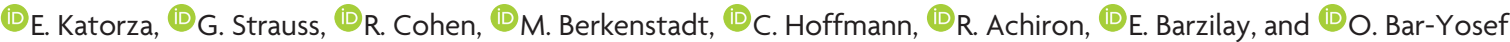

\begin{abstract}
BACKGROUND AND PURPOSE: One of the perplexing findings of fetal brain MR imaging is white matter T2 hyperintense signal. The aims of our study were initially to determine the main etiologies associated with white matter T2 hyperintense signal, then to examine whether the different etiologies have different ADC values, and, last, to assess the association of white matter T2 hyperintense signal with developmental outcome.
\end{abstract}

MATERIALS AND METHODS: This was a prospective cohort study of $44 \mathrm{MR}$ imaging scans of fetal brains obtained for suspected brain pathologies at a tertiary medical center during 2011-2015. Clinical data were collected from electronic medical charts. ADC values were measured and averaged in the frontal, parietal, occipital, and temporal lobes. Neurodevelopmental assessments were performed with the Vineland Adaptive Behavior Scales II.

RESULTS: Half of the cases of MRI hyperintense T2 signal of the fetal brain were associated with congenital cytomegalovirus infection. The other half were mainly idiopathic. Thus, the study group was divided to subgroups positive and negative for cytomegalovirus. Both groups had hyperintense signal in the temporal lobe. The group positive for cytomegalovirus had involvement of the parietal lobe. Only this group had increased ADC values in the temporal and parietal lobes. There was no association between the neurodevelopment outcome and the etiologies or ADC values.

CONCLUSIONS: T2 hyperintense signal in fetal brain MRI associated with positive cytomegalovirus infection has increased ADC values in the temporal and parietal lobes, suggestive of brain edema in these areas. However, the association between this finding and neurodevelopment outcome requires further evaluation.

ABBREVIATIONS: CMV = cytomegalovirus; fbMRI = fetal brain MRI; ICC = interclass correlation coefficient; VABS = Vineland Adaptive Behavior Scales II; WMHS = white matter hyperintense signal

etal brain MR imaging (fbMRI) has been increasingly used in
recent years as a means of tracking normal and pathologic fetal brain maturation. ${ }^{1}$ One of the perplexing findings of fbMRI is white matter T2 hyperintense signal (WMHS). On the one hand, it has been associated with in utero brain pathologies, such as ischemia and cytomegalovirus (CMV) infection. ${ }^{2-4}$ On the other

Received February 26, 2018; accepted after revision July 19

From the Antenatal Diagnostic Unit (E.K., G.S., R.C., R.A., E.B.), Department of Obstetrics and Gynecology, Pediatric Neurology Unit (O.B.-Y.), The Danek Gertner Institute of Human Genetics (M.B.), and Neuroradiology Unit (C.H.), Department of Diagnostic Radiology, Chaim Sheba Medical Center, Tel-Hashomer, Israel; and Sackler School of Medicine (E.K., G.S., R.C., M.B., C.H., R.A., E.B., O.B.-Y.), Tel Aviv University, Tel Aviv, Israel.

E. Katorza and G. Strauss contributed equally to this work.

Please address correspondence to Omer Bar-Yosef, MD, PhD, Pediatric Neurology Unit, Department of Pediatrics, Chaim Sheba Medical Center, Tel-Hashomer 5262100, Ramat Gan, Israel; e-mail: omerbary@gmail.com

http://dx.doi.org/10.3174/ajnr.A5802 hand, the validity and relevance of this finding have been questioned. $^{5}$

In recent years, DWI and its ADC metric have become a quantitative method for evaluation of fetal brain maturation. ${ }^{6}$ Previous studies showed that ADC values of the developing fetal brain correlate with fetal brain maturation. ${ }^{7-11}$ Deviation from normal ADC values has been shown to be associated with brain pathologies such as ischemia, CMV infection, and ventriculomegaly. ${ }^{2,12,13}$ Postmortem studies of animal and human fetuses with hypoxic-ischemic brain injury have demonstrated a transition from low ADC values after the injury to increased values 7 days after the injury. This transition was associated with histologic findings changing from initial cytotoxic edema and swollen astrocytes to vasogenic edema, astrogliosis, and abundance of macrophages. ${ }^{2,14}$ Thus, ADC and its association with histopathology could be used to test the validity and meaning of T2 hyperintensity.

The aims of our study were initially to determine the main 
etiologies associated with WMHS, then to examine whether the different etiologies have different ADC values, and, last, to assess the association of WMHS with developmental outcome.

\section{MATERIALS AND METHODS \\ Subjects}

This was a prospective cohort study of women who were referred for fetal brain MR imaging to our tertiary medical center, Sheba Medical Center, Ramat Gan, Israel, between 2011 and 2015. The cohorts for this study were chosen on the basis of identification of a hyperintense signal on the T2-weighted sequences. Demographic and clinical data were collected from the electronic records of each patient.

Data obtained from the records included maternal history, prenatal screening tests, imaging results from anatomic sonography and MR imaging, maternal CMV status, and perinatal history. Fetal cytomegalovirus infection was confirmed by either amniocentesis performed during pregnancy or by the presence of CMV DNA in neonatal urine or saliva.

The study was approved by Sheba Medical Center, Ramat Gan, Israel, institutional ethics board. Informed consent was obtained from each participant in the study prospectively.

\section{MR Imaging Scans}

Fetal brain MR imaging was performed using a $1.5 \mathrm{~T}$ system (Optima MR450w with GEM Suite; GE Healthcare, Milwaukee, Wisconsin). Single-shot fast spin-echo T2-weighted sequences in 3 orthogonal planes were performed using a half-Fourier technique $(\mathrm{NEX}=0.53)$ with the following parameters: section thickness, 3 or $4 \mathrm{~mm}$; no gap; flexible coil (8-channel cardiac coil). FOV was determined by the size of the fetal head with a range of $24 \times 24$ to $30 \times 30 \mathrm{~cm}$; acquisition time was between 40 and 45 seconds (matrix, $320 \times 224$; TE, 90 ms; TR, 1298 ms; pixel bandwidth, $122 \mathrm{~Hz} /$ pixel; specific absorption rate values, 1.1$1.7 \mathrm{~W} / \mathrm{kg}$ ). A DWI sequence in 1, 2, or 3 orthogonal planes was then performed, with a $40-\mathrm{cm}$ FOV, b-values of 0 and $700 \mathrm{~ms}$, and a slice thickness of $4 \mathrm{~mm}$ with no gap. All MR images were obtained by the same protocol at our institution and assessed by a specialist in fetal sonography and a neuroradiologist expert in MR imaging as previously published. ${ }^{15}$

\section{Target Variables}

ADC calculation was performed on 8 circular ROIs: 2 on the white matter of both frontal, parietal, temporal, and occipital lobes. A circular ROI was used, placed over the desired anatomic area, ranging from 75 to $98 \mathrm{~mm}^{2}$, similar to that accepted in the recent literature. ${ }^{11}$ Examples of ROI placements over the various anatomic areas can be seen in Fig 1. The ROIs were placed with the following anatomic considerations: Frontal lobe ROIs were placed in the anterior part of the frontal lobes above the lateral ventricles, parietal lobe ROIs were placed in the posterior part of the parietal lobes above the lateral ventricles, temporal lobe ROIs were placed anterior to the temporal horns, and occipital lobe ROIs were placed posterior to the lateral ventricles. The ADC was calculated using IntelliSpace workstation software (Phillips Healthcare, Best, the Netherlands; https://www. usa.philips.com/healthcare/solutions/clinical-informatics/ enterprise-imaging-pacs).

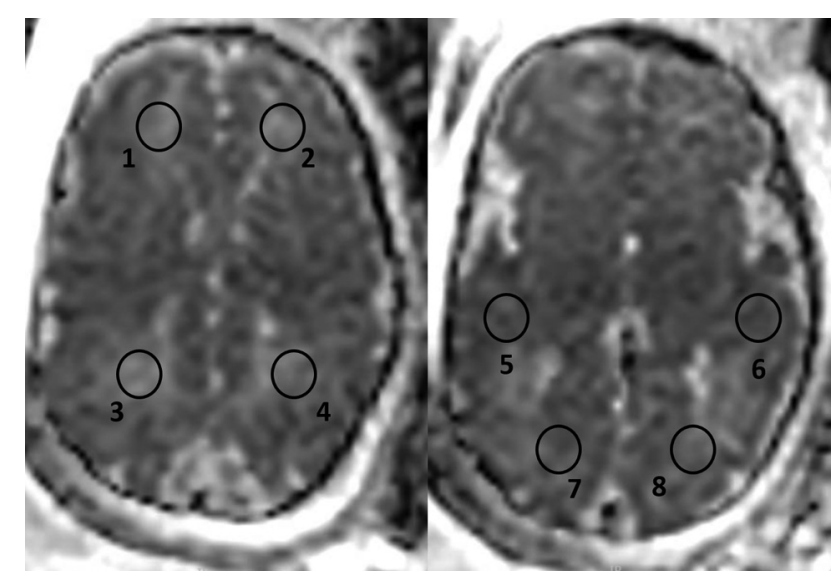

FIG 1. ADC calculation was performed on 8 circular ROIs: 2 on the white matter of both frontal $(1,2)$, parietal $(3,4)$, temporal $(5,6)$, and occipital lobes $(7,8)$. A circular ROI was placed over the desired anatomic area, ranging from 75 to $98 \mathrm{~mm}^{2}$.

\section{White Matter T2 Hyperintense Signal}

WMHS is a subjective interpretation of the signal from the fetal brain white matter on $\mathrm{T} 2$ sequences, made by the radiologist. This diagnosis is established when specific areas of the brain white matter appear hyperintense in comparison with other areas or with that expected according to the gestational age (Fig 2). ${ }^{16}$

\section{Interobserver Validity of ADC Measurements}

To validate the consistency of measurements and reliability of results, 2 observers evaluated 10 fetuses. Interobserver variability was assessed by the interclass correlation coefficient (ICC). We considered an ICC value of $\geq 0.8$ as excellent agreement.

\section{Neurodevelopmental and Hearing Outcome}

Children were assessed by the Vineland Adaptive Behavior Scales, 2nd edition (VABS), which is a structured parent interview assessing 4 different domains of behavior: communication, daily living skills, socialization, and motor skills. All 4 domains are included in an adaptive composite score. ${ }^{17,18}$ VABS assessment was conducted by a phone interview by 2 medical students trained and supervised by a pediatric neurologist and child development expert experienced in conducting VABS (O.B.-Y.). Validation of the phone interviews were assessed by correlation of the ICC to the VABS scores of 15 children (divided into 7 and 8 children between the students) evaluated by the pediatric neurologist (O.B.-Y.). The ICC was $>0.83$ for the 4 VABS domains and the composite score. Scores of children were considered abnormal if the standard score was $<70$.

Hearing outcome was assessed 2-3 days after delivery by Transient Evoked Otoacoustic Emissions. Neonates positive for CMV were tested routinely before 1 month of age by brain stem auditory evoked potential, then at 3, 6, and 12 months by Transient Evoked Otoacoustic Emissions and behavioral assessment.

\section{Statistical Analysis}

Categoric variables were expressed as number and percentage. Distribution of continuous variables was assessed using a histo- 

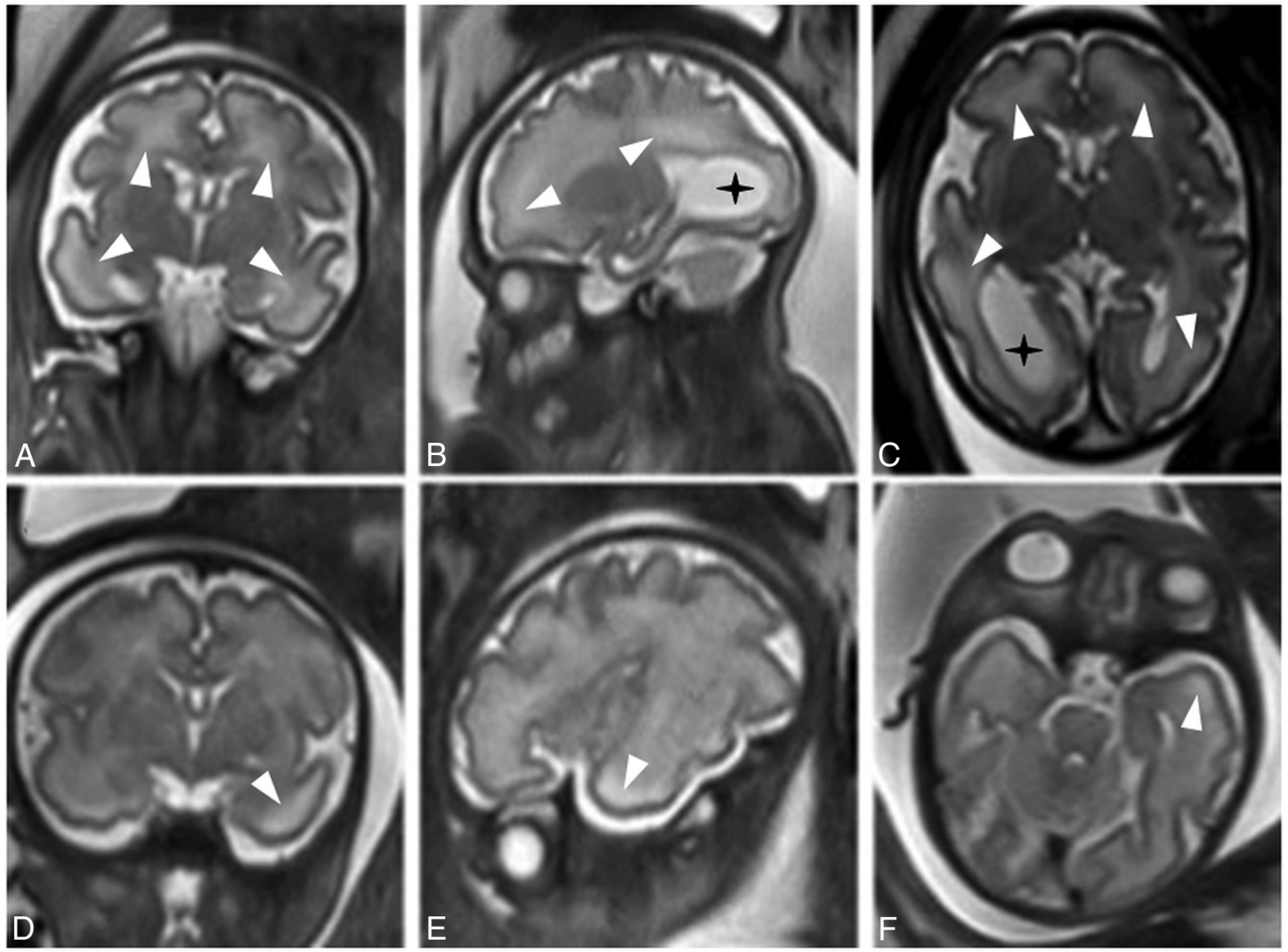

FIG 2. T2 MR images (single-shot fast spin-echo T2-weighted sequences in 3 orthogonal planes using a half-Fourier technique, NEX $=0.53$ ) of 2 fetuses at 33 weeks of gestational age. The CMV-positive fetus has diffuse WMHS (white arrowheads), unilateral ventriculomegaly, and intraventricular adhesions (black asterisks), suggesting ventriculitis $(A-C)$. The CMV-negative fetus has WMHS located in the white matter in the temporal lobes (white arrowhead) (D-F).

Table 1: Demographic and clinical characteristics of fetuses with white matter T2 hyperintense signal ${ }^{\mathrm{a}}$

\begin{tabular}{|c|c|c|c|}
\hline Characteristic & $\begin{array}{l}\text { CMV-Positive } \\
(n=22)\end{array}$ & $\begin{array}{l}\text { CMV-Negative } \\
\quad(n=22)\end{array}$ & $\begin{array}{c}P \\
\text { Value }\end{array}$ \\
\hline Maternal age (yr) & $30.5(26.7-34.2)$ & $31(28.7-34.2)$ & .74 \\
\hline Gestational age at MRI (wk) & $33(32-34)$ & $33.5(32-35)$ & .69 \\
\hline Previous pregnancies & $2(2-3)$ & $2(1-4)$ & .94 \\
\hline Previous labors & $1(1-1.75)$ & $1(0-2.25)$ & .95 \\
\hline Abnormal outcome in previous labors & $6(27 \%)$ & $7(32 \%)$ & .74 \\
\hline Abnormal maternal medical background & 0 & $6(27 \%)$ & .02 \\
\hline $\begin{array}{l}\text { Mode of conception } \\
\text { Spontaneous }\end{array}$ & $19(86 \%)$ & $22(100 \%)$ & .35 \\
\hline IVF & $2(9 \%)$ & $0(0 \%)$ & \\
\hline Induced pregnancy & $1(5 \%)$ & $0(0 \%)$ & \\
\hline Sex (male) & $12(54 \%)$ & $8(38 \%)$ & .36 \\
\hline Normal nuchal translucency scan results & $21(95 \%)$ & $22(100 \%)$ & .99 \\
\hline Normal first trimester biochemical test results & $21(94 \%)$ & $21(94 \%)$ & $>.99$ \\
\hline Normal second trimester biochemical test results & $22(100 \%)$ & $22(100 \%)$ & $>.99$ \\
\hline Normal early anatomic scan findings & $22(100 \%)$ & $16(72 \%)$ & .02 \\
\hline Normal late anatomic scan findings & $21(94 \%)$ & $11(60 \%)$ & .009 \\
\hline
\end{tabular}

Note:-IVF indicates in vitro fertilization.

${ }^{a}$ Data are presented as median (interquartile range) for continuous variables or number (percentage) for categoric variables.

gram and Q-Q plot. Continuous variables were described using median and interquartile range or mean and SD as appropriate. Categoric variables were compared using the $\chi^{2}$ test, Fisher exact test, or McNemar test as appropriate. Continuous variables were compared using the Student $t$ test or Mann-Whitney test as appropriate. A 2-tailed $P<$ .05 was considered statistically significant. Analyses were performed with SPSS (Version 24.0, 2016; IBM, Armonk, New York).

\section{RESULTS}

\section{Demographic and Clinical Characteristics of the Study Population}

The study subjects comprised 43 singleton pregnant women and 1 single twins pregnant woman who underwent $\mathrm{fb}$ MRI scans. All 44 fetuses included in this study were in their third trimester of pregnancy at the time of the fetal MR imaging, with a median gestational age of 32 weeks (interquartile range, 28.25-35 weeks). The average maternal age was 33 years (interquartile range, 25-32 years). The indications for MR imaging included the following: maternal cy- 
Table 2: Radiologic MR imaging findings ${ }^{\mathrm{a}}$

\begin{tabular}{lccc}
\hline & CMV-Positive & CMV-Negative & $P$ Value \\
\hline Gestational age at MRI (wk) & $33(32-34)$ & $33.5(32-35)$ & .6 \\
Radiologic finding & & & \\
$\quad$ Frontal T2 hyperintense signal & $13 / 22(59 \%)$ & $6 / 22(27.3 \%)$ & .067 \\
$\quad$ Parietal T2 hyperintense signal & $14 / 22(63.6 \%)$ & $3 / 22(13.6 \%)$ & .002 \\
$\quad$ Temporal T2 hyperintense signal & $22 / 22(100 \%)$ & $21 / 22(95.5 \%)$ & $>.999$ \\
Occipital T2 hyperintense signal & $0 / 22(0 \%)$ & $0 / 22(0 \%)$ & $>.999$ \\
$\quad$ T2 hyperintense signal at 3 lobes (frontal, & $13 / 22(59 \%)$ & $3 / 22(13 / 6 \%)$ & .004 \\
$\quad$ parietal, and temporal) & $1 / 22(4.5 \%)$ & $7 / 22(31.8 \%)$ & .046 \\
$\quad$ Additional findings & & & \\
\hline
\end{tabular}

${ }^{a}$ Data are presented as median (interquartile range) for continuous variables or number (percentage) for categoric variables.

Table 3: Comparison of ADC values of the study group with the control group ${ }^{a}$

\begin{tabular}{ccccc}
\hline Lobe, Side & Study Group & ADC & ADC Control & $P$ Value \\
\hline Frontal & & & & \\
Right & CMV- & $1793(191)$ & $1809(165)$ & .754 \\
Right & CMV+ & $1872(160)$ & & .160 \\
Left & CMV- & $1741(141)$ & & .115 \\
Left & CMV+ & $1858(193)$ & & .302 \\
Parietal & & & & .099 \\
Right & CMV- & $1659(200)$ & $1748(192)$ & .057 \\
Right & CMV+ & $1840(140)$ & & .268 \\
Left & CMV- & $1690(188)$ & & .03 \\
Left & CMV+ & $1852(138)$ & & \\
Temporal & & & & .843 \\
Right & CMV- & $1702(169)$ & $1692(164)$ & .002 \\
Right & $\mathrm{CMV}+$ & $1835(161)$ & & .933 \\
Left & $\mathrm{CMV}-$ & $1689(193)$ & & $<.001$ \\
Left & $\mathrm{CMV}+$ & $1846(122)$ & & .171 \\
Occipital & & & & .830 \\
Right & $\mathrm{CMV}-$ & $1659(224)$ & $1731(167)$ & .224 \\
Right & $\mathrm{CMV}+$ & $1723(129)$ & & .882 \\
Left & $\mathrm{CMV}-$ & $1675(169)$ & & \\
Left & $\mathrm{CMV}+$ & $1725(111)$ & & \\
\hline
\end{tabular}

Note:-CMV+ indicates CMV-positive; CMV - , CMV-negative.

${ }^{a}$ Data are presented as mean (SD). ADC units are $10^{6} \mathrm{~mm}^{2} / \mathrm{s}$.

tomegalovirus infection $(n=31)$, family history of central nervous system pathology $(n=3)$, and abnormal findings during fetal sonography $(n=10)$. The abnormal sonographic findings included the following: lateral ventricular asymmetry $(n=4)$, mega cisterna magna $(n=2)$, small head circumference $(n=2)$, fisted hands $(n=1)$, and hyperechogenic bowel $(n=1)$. Twentytwo $(50 \%)$ of the fetuses were found to be positive for CMV by amniocentesis or by saliva or urinary CMV DNA testing after birth. Thus, to examine the association between ADC values and etiology, we divided the main study group into a CMV-positive group consisting of 22 fetuses with confirmed CMV infection and a CMV-negative group consisting of 22 fetuses with WMHS from an unknown etiology.

These 2 distinct patient populations are described separately and compared by their demographic, clinical, imaging, and neurodevelopment characteristics.

The median gestational age, pregnancy history, and sex did not differ statistically between the groups. All mothers in the $\mathrm{CMV}$-positive group had normal medical background, compared with $6(27 \%)$ mothers in the CMV-negative group who had significant abnormal medical background including thrombophilia, Raynaud disease, and a history of cerebellar infarction $(P=.02)$.
In the CMV-positive group, there were significantly less early and late anatomic scan findings $(P=.02, P=$ .009 , respectively) (Table 1 ).

\section{Distribution of Hyperintense Signal and Additional MR Imaging Findings}

Both groups had similar rates of WMHS in the temporal lobe $(P>$ .999). WMHS was not depicted in the occipital lobe in both groups. However, the CMV-positive group had statistically higher rates of parietal hyperintense signal $(P=.002)$ and a trend toward higher rates in the frontal lobe $(P=.067)$. The CMV-positive group had more extended WMHS involving all 3 lobes $(P=.004)$. The CMV-negative fetuses had statistically significantly higher rates $(P=.046)$ of minor additional findings on imaging, including subarachnoid cyst $(n=2)$, slightly enlarged subarachnoid space $(n=1)$, and lateral ventricle asymmetry $(n=4)$ (Table 2 and Fig 2).

\section{Interobserver Validity of ADC Measurements}

ADC measurements showed excellent interobserver agreement for all regions, with the ICC ranging between 0.81 and 0.97 .

\section{ADC Value Measurements}

ADC values for each group were compared with the normal ADC values as published by Hoffmann et al. ${ }^{11}$ Fetuses in the CMVpositive group were found to have statistically higher ADC values in the temporal lobe bilaterally $(P=.002$ and $P<.001)$ and the left parietal lobe $(P=.033)$ and a trend in the right parietal lobe $(P=.057)$ (Table 3$)$.

$\mathrm{ADC}$ values were compared for each region between the 2 study groups. Fetuses in the CMV-positive group were found to have higher ADC values in the left frontal lobe $(P=.026)$, the parietal lobe bilaterally (right, $P=.001$; left, $P=.002$ ), and the temporal lobe bilaterally (right, $P=.011$; left, $P=.002$ ) (Table 4 ).

\section{Delivery Data, Hearing, and Neurodevelopmental Assessment}

Neurodevelopmental assessment (VABS) and delivery data were analyzed for 20 children in the CMV-positive group and 18 children in the CMV-negative group (Table 5). Six patients (2 from the CMV-positive group and 4 from the CMV-negative group) refused to participate in the neurodevelopmental assessment. Delivery data and age at developmental assessment were not statistically different between the groups. Comparison of the VABS score for the 4 domains and the adaptive composite score showed only 
a trend for motor skills $(P=.07)$. Four children in the CMVpositive group and 1 child in the CMV-negative group had at least 1 VABS score $<70$; however, this was not statistically significant. Only 1 child had a hearing deficit; this child was CMV-positive with a low VABS score.

\section{DISCUSSION}

WMHS is a puzzling finding in fetal MR imaging, and its significance is not completely understood. The aims of our study were initially to explore the etiologies associated with this finding, then to examine whether the different etiologies are characterized by different ADC values, and, last, to investigate the association of WMHS with neurodevelopmental outcome.

Diverse etiologies were found to be associated with WMHS in this study. The major one (half of the study group), in accordance with fetal MR imaging literature, is congenital CMV infection. ${ }^{13,19,20}$ The precise etiologies of the second half of the group are not completely clear. Ten fetuses had further imaging findings; thus, the WMHS might be a different aspect of the overall brain pathology.

Comparison between the 2 groups demonstrated a difference in the distribution of the WMHS. Both groups had the same prevalence of WMHS in the temporal lobes, but the CMV-positive group had a higher rate in the parietal lobes and a trend in the frontal lobes. In general, the CMV-positive group had more diffuse WMHS.

The median ADC values were higher in the CMV-positive group than in the CMV-negative group in the temporal, parietal,

\begin{tabular}{|c|c|c|c|}
\hline Lobe, Side & CMV-Positive & CMV-Negative & $P$ Value \\
\hline \multicolumn{4}{|l|}{ Frontal } \\
\hline Right & 1872 (160) & 1793 (192) & .147 \\
\hline Left & 1858 (193) & $1741(141)$ & .026 \\
\hline \multicolumn{4}{|l|}{ Parietal } \\
\hline Right & 1840 (140) & 1659 (200) & .001 \\
\hline Left & 1852 (138) & 1690 (188) & .002 \\
\hline \multicolumn{4}{|l|}{ Temporal } \\
\hline Right & 1835 (161) & 1702 (169) & .011 \\
\hline Left & 1846 (122) & 1689 (193) & .002 \\
\hline \multicolumn{4}{|l|}{ Occipital } \\
\hline Right & 1723 (129) & 1659 (224) & .259 \\
\hline Left & 1725 (117) & 1675 (169) & .254 \\
\hline
\end{tabular}

${ }^{a}$ Data are presented as mean (SD). ADC units are $10^{6} \mathrm{~mm}^{2} / \mathrm{s}$.

Table 5: Delivery data, hearing, and VABS assessment ${ }^{\mathrm{a}}$

\begin{tabular}{lccc}
\multicolumn{1}{c}{ Characteristic } & $\begin{array}{c}\text { CMV-Positive } \\
(\boldsymbol{n}=\mathbf{2 0})\end{array}$ & $\begin{array}{c}\text { CMV-Negative } \\
(\boldsymbol{n}=18)\end{array}$ & $\boldsymbol{P}$ Value \\
\hline Birth week & $39.2(38.5-39.9)$ & $37.9(39.7-40.6)$ & .55 \\
Birth weight (percentile) & $49(31-73)$ & $49(13-68)$ & .53 \\
Apgar score at 5 min $\geq 9$ & $20(100 \%)$ & $18(100 \%)$ & $>.99$ \\
Hearing deficit & $1(5 \%)$ & $0(0 \%)$ & $>.99$ \\
Age (mo) at VABS test & $30(17-49)$ & $27.5(17.2-28.5)$ & .75 \\
VABS motor skills & $92.5(81.75-104)$ & $103(95.25-108)$ & .07 \\
VABS daily living skills & $103(99.25-117)$ & $109(99.25-117)$ & .28 \\
VABS socialization & $101(98.5-105.75)$ & $100(96.75-115.75)$ & .89 \\
VABS communication & $107.5(100.25-113)$ & $108(99.25-117)$ & .84 \\
VABS adaptive score composite & $102(90-18)$ & $107(98-115)$ & .16 \\
Child with any VABS score $<70$ & $4(20 \%)$ & $1(5.5 \%)$ & .34 \\
\hline
\end{tabular}

${ }^{a}$ Data are presented as median (interquartile range) for continuous variables or as number (percentage) for categoric variables.

${ }^{\mathrm{b}}$ Hearing deficit was assessed by either transient evoked otoacoustic emissions or brain stem evoked potential. and left frontal lobes. The ADC values of the CMV-negative group did not differ from those of the control group. Thus, although the incidences of WMHS were similar in the temporal lobes, the median ADC values were different. Because ADC is a quantitative measure and not a subjective interpretation, it is possible that some WMHS of the CMV-negative group is actually overinterpretation.

As for the CMV-positive group, the specific involvement of the temporal lobes was previously described in fbMRI. WMHS is part of a spectrum of findings localized to this area, including cysts, dilation of the temporal horns, and reduced temporal lobe volume. ${ }^{4,11,21,22}$ The reason for the specific vulnerability of the temporal lobe is unclear. Most interesting, in addition to the presence of WMHS in the temporal lobe, most of the fbMRIs in our study depicted a similar signal in the parietal lobe. This finding was previously described in children with congenital CMV. ${ }^{23-25}$ Thus, the combination of temporal and parietal hyperintense T2 signal is potentially a sign of CMV infection involving the brain. Further involvement of WMHS including the frontal lobes may serve as an additional sign of congenital CMV infection.

The combination of WMHS and high ADC values in the CMV-positive group suggests a possible etiology for this finding. Hyperintense signal was associated at postmortem examination with astrogliosis and extracellular brain edema in the subacute stage of hypoxic-ischemic injury. ${ }^{2}$ Although hypoxic-ischemic injury pathogenesis is different from CMV infection, the simplest explanation of the T2 finding is an increase in extracellular fluid content in the white matter. Kotovich et $\mathrm{al}^{26}$ found low ADC values in fetuses with congenital CMV infection without T2 hyperintense signal. In a previous study of the same group, Yaniv et $\mathrm{al}^{4}$ described postmortem histology consisting of edema and cellular infiltration of plasma cells, lymphocytes, and microglia. The difference in T2 hyperintense signal and ADC values between the 2 latter studies and ours might reflect a different ratio between the edema and cellular component in the brain tissue. When the microgliosis and edema component are more prominent, the $\mathrm{ADC}$ values are larger than those of controls; whereas when the component of cellular degeneration and immune cell infiltration is more prominent, the ADC values are lower than those of controls. ${ }^{2,14,27-29}$

The association between WMHS and abnormal neurodevelopmental outcome was not found in this study. In the CMVpositive group, 4 children (20\%) had abnormal neurodevelopmental findings or hearing loss. Based on neurodevelopmental data from previous studies, the expected range of these abnormal findings in children with asymptomatic congenital CMV (normal prenatal imaging findings) is $10 \%-$ $15 \% .^{30,31}$ Thus, it is difficult to assess whether the WMHS and the increased ADC values predict worse prognosis.

Combining the results from our study and others ${ }^{2,11-14,26}$ investigating the association of ADC and brain pathologies suggests the following practical advice for clinicians: The combination of WMHS and normal ADC 
suggests that the source of WMHS is most likely without clinical significance. As for cases of abnormal ADC either below or above the expected value for gestational age, they raise the suspicion of brain pathology such as CMV infection, ventriculomegaly, or ischemia. However, the association of abnormal ADC with neurodevelopmental outcome is unclear.

Our study is limited by the size of the study group. A larger number of patients could be used to correlate the distribution of T2 hyperintense signal or ADC values with neurodevelopment. On the other hand, the small number of children in each group strengthens the significance of the difference in T2 hyperintense signal and $\mathrm{ADC}$ values between the CMV-positive and -negative groups.

\section{CONCLUSIONS}

ADC measurements supported the validity of T2 hyperintense signal in fbMRI only in fetuses with CMV infection. The association of this finding with neurodevelopmental outcome requires further investigation.

\section{REFERENCES}

1. Griffiths PD, Bradburn M, Campbell MJ, et al MERIDIAN collaborative group. Use of MRI in the diagnosis of fetal brain abnormalities in utero (MERIDIAN): a multicentre, prospective cohort study. Lancet 2017;389:538-46 CrossRef Medline

2. Guimiot F, Garel C, Fallet-Bianco C, et al. Contribution of diffusionweighted imaging in the evaluation of diffuse white matter ischemic lesions in fetuses: correlations with fetopathologic findings. AJNR Am J Neuroradiol 2008;29:110-115 CrossRef Medline

3. Malinger G, Lev D, Lerman-Sagie T. Imaging of fetal cytomegalovirus infection. Fetal Diagn Ther 2011;29:117-26 CrossRef Medline

4. Yaniv G, Hoffmann C, Weisz B, et al. Region-specific reductions in brain apparent diffusion coefficient in cytomegalovirusinfected fetuses. Ultrasound Obstet Gynecol 2016;47:600-07 CrossRef Medline

5. Fazekas F, Kleinert R, Offenbacher H, et al. Pathologic correlates of incidental MRI white matter signal hyperintensities. Neurology 1993;43:1683-89 CrossRef Medline

6. Schneider JF, Confort-Gouny S, Le Fur Y, et al. Diffusion-weighted imaging in normal fetal brain maturation. Eur Radiol 2007;17: 2422-29 CrossRef Medline

7. Sartor A, Arthurs O, Alberti C, et al. Apparent diffusion coefficient measurements of the fetal brain during the third trimester of pregnancy: how reliable are they in clinical practice? Prenat Diagn 2014;34:357-66 CrossRef Medline

8. Neil JJ, Shiran SI, McKinstry RC, et al. Normal brain in human newborns: apparent diffusion coefficient and diffusion anisotropy measured by using diffusion tensor MR imaging. Radiology 1998; 209:57-66 CrossRef Medline

9. Girard N, Confort-Gouny S, Schneider J, et al. MR imaging of brain maturation. J Neuroradiol 2007;34:290-310 CrossRef Medline

10. Toft $P B$, Leth $H$, Peitersen $B$, et al. The apparent diffusion coefficient of water in gray and white matter of the infant brain. J Comput Assist Tomograph 1996;20:1006-11 CrossRef Medline

11. Hoffmann C, Weisz B, Lipitz S, et al. Regional apparent diffusion coefficient values in 3rd trimester fetal brain. Neuroradiology 2014; 56:561-67 CrossRef Medline

12. Erdem G1, Celik O, Hascalik, et al. Diffusion-weighted imaging evaluation of subtle cerebral microstructural changes in intrauterine fetal hydrocephalus. Magn Reson Imaging 2001;25:417-22 Medline

13. Yaniv G, Katorza E, Bercovitz R, et al. Region-specific changes in brain diffusivity in fetal isolated mild ventriculomegaly. Eur Radiol 2016;26:840-48 CrossRef Medline

14. Baud O, Daire JL, Dalmaz Y, et al. Gestational hypoxia induces white matter damage in neonatal rats: a new model of periventricular leukomalacia. Brain Pathol 2004;14:1-10 CrossRef Medline

15. Gat I, Hoffmann C, Shashar D, et al. Fetal brain MRI: novel classification and contribution to sonography. Ultraschall Med 2016;37: 176-84 CrossRef Medline

16. Lipitz S, Hoffmann C, Feldman B, et al. Value of prenatal ultrasound and magnetic resonance imaging in assessment of congenital primary cytomegalovirus infection. Ultrasound Obstet Gynecol 2010;36: 709-17 CrossRef Medline

17. Limperopoulos C, Majnemer A, Steinbach CL, et al. Equivalence reliability of the Vineland Adaptive Behavior Scale between in-person and telephone administration. Phys Occup Ther Pediatr 2006;26: 115-27 Medline

18. Sparrow SS. Cicchetti D, Balla DA. Vineland Adaptive Behavior Scales. 2nd ed. San Antonio; Pearson: 2005

19. Oosterom N, Nijman J, Gunkel J, et al. Neuro-imaging findings in infants with congenital cytomegalovirus infection: relation to trimester of infection. Neonatology 2015;107:289-96 CrossRef Medline

20. de Vries LS, Gunardi H, Barth PG, et al. The spectrum of cranial ultrasound and magnetic resonance imaging abnormalities in congenital cytomegalovirus infection. Neuropediatrics 2004;35: 113-19 CrossRef Medline

21. Cannie MM, Devlieger R, Leyder M, et al. Congenital cytomegalovirus infection: contribution and best timing of prenatal MR imaging. Eur Radiol 2016;26:3760-69 CrossRef Medline

22. Doneda C, Parazzini C, Righini A, et al. Early cerebral lesions in cytomegalovirus infection: prenatal MR imaging. Radiology 2010; 255:613-21 CrossRef Medline

23. van der Knaap MS, Vermeulen G, Barkhof F, et al. Pattern of white matter abnormalities at MR imaging: use of polymerase chain reaction testing of Guthrie cards to link pattern with congenital cytomegalovirus infection. Radiology 2004;230:529-36 CrossRef Medline

24. Manara R, Balao L, Baracchini C, et al. Brain magnetic resonance findings in symptomatic congenital cytomegalovirus infection. $P e$ diatr Radiol 2011;41:962-70 CrossRef Medline

25. Hart CK, Wiley S, Choo DI, et al. Developmental disabilities and intracranial abnormalities in children with symptomatic cytomegalovirus and cochlear implants. ISRN Otolaryngol 2012;2012:502746 CrossRef Medline

26. Kotovich D, Guedalia JS, Hoffmann C, et al. Apparent diffusion coefficient value changes and clinical correlation in 90 cases of cytomegalovirus-infected fetuses with unremarkable fetal MRI results. AJNR Am J Neuroradiol 2017;38:1443-48 CrossRef Medline

27. Vannucci RC, Christensen MA, Yager JY. Nature, time-course, and extent of cerebral edema in perinatal hypoxic-ischemic brain damage. Pediatr Neurol 1993;9:29-34 CrossRef Medline

28. Lodygensky GA, West T, Moravec MD, et al. Diffusion characteristics associated with neuronal injury and glial activation following hypoxia-ischemia in the immature brain. Magn Reson Med 2011;66: 839-45 CrossRef Medline

29. Miller SP, Vigneron DB, Henry RG,et al. Serial quantitative diffusion tensor MRI of the premature brain: development in newborns with and without injury. J Magn Reson Imaging 2002;16:621-62 CrossRef Medline

30. Naing ZW, Scott GM, Shand A, et al. Congenital cytomegalovirus infection in pregnancy: a review of prevalence, clinical features, diagnosis and prevention. Aust N Z J Obstet Gynaecol 2016;56:9-18 CrossRef Medline

31. Lipitz S, Yinon Y, Malinger G, et al. Risk of cytomegalovirus-associated sequelae in relation to time of infection and findings on prenatal imaging. Ultrasound Obstet Gynecol 2013;508-14 CrossRefMedline 